Case Report

\title{
A rare case of gingival myeloid sarcoma in a child
}

\author{
Vishwanath Meghashree ${ }^{1}$, Rao S Purnima², Pai R Muktha ${ }^{3}$ \\ ${ }^{1,2,3}$ Department of Pathology, A. J. Institute of Medical Sciences and Reseach centre, Mangalore, \\ India
}

\section{Keywords:}

Burkitt;

Intraoral;

Lymphoma;

Myeloid;

Non Hodgkin;

Sarcoma

\section{ABSTRACT}

Myeloid sarcoma is a rare tumour composed of immature myeloid cells. Its occurrence in childhood is rare. Only a few cases of intraoral myeloid sarcoma have been reported in literature. We present a case of myeloid sarcoma with simultaneous involvement of intraoral soft tissues and lymph node. Here, importance is given to suspect this frequently mis diagnosed disease.

\section{Correspondence:}

Dr. Meghashree V

Postgraduate, Department of Pathology

A. J. Institute of Medical Sciences and Reseach centre, Mangalore-575004, India

ORCID ID: 0000-0002-5616-2725

Email: v.megharox@gmail.com

Received : July 2nd, 2017 ; Accepted : August 12th, 2017; Published : September 1, 2017

Citation: Vishwanath M., Rao SP, Pai RM. A rare case of Gingival Myeloid sarcoma in a child. J

Pathol Nep. 2017;7:1227-30. doi: 10.3126/jpn.v\%vi\%i.18039

Copyright: This is an open-access article distributed under the terms of the Creative Commons Attribution 4.0 International License, which permits unrestricted use, distribution, and reproduction in any medium, provided the original author and source are credited.

\section{INTRODUCTION}

Myeloid sarcoma (MS) is a tumour mass of myeloblasts with or without maturation occurring outside the bone marrow. These rare extramedullary myeloid tumours may occur denovo, or coexist with or follow the presentation of Acute Myeloid Leukemia (AML). Myeloid sarcoma can also arise as blastic transformation of an underlying chronic myeloproliferative disease or myelodysplastic syndrome. ${ }^{1}$ Presence of intraoral myeloid sarcoma is rare ${ }^{2}$ with about 45 cases reported in literature. We present a case of gingival myeloid sarcoma masquerading as Non Hodgkins lymphoma.

\section{CASE REPORT}

A 11- month- old boy had an alleged history of fall one month prior to the development of an intraoral swelling measuring $7 \times 5 \mathrm{~cm}$ (fig.1a) and a post auricular swelling $(3 \times 2 \mathrm{~cm})$ on the right side (fig.1b). The child also had 


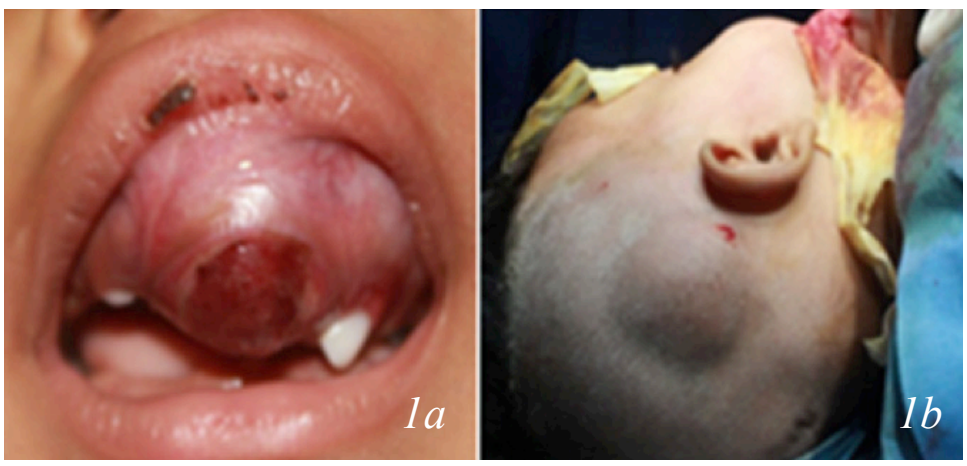

Figure 1 : Intraoral swelling (a) with focal ulceration along with postauricular swelling (b)
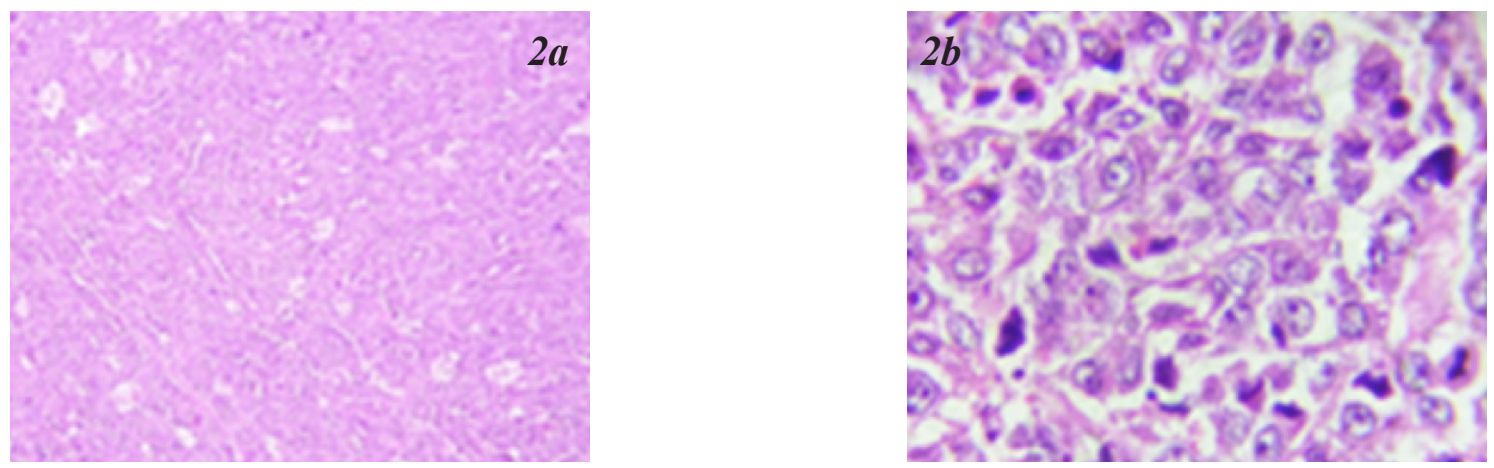

Figure 2a: Photomicrograph showing tumour tissue exhibiting 'starry sky pattern. (HE stain; X10). 2b: High power view from post auricular lymph node showing diffuse effacement with large cells with vesicular nucleus having prominent nucleoli along with numerous apoptotic bodies and mitotic figures. (HE stain; X100)

a history of dental extraction 7 days back following which there was increase in the size of intraoral swelling and the redness. Excision and curettage of both swellings was done and sent for histopathological examination. Intraoral swelling was a cystic mass and fluid aspirated from the mass showed numerous tingible body macrophages admixed with atypical cells in a background of mixed inflammatory cells. Sections studied from the intraoral cystic mass revealed keratinised and ulcerated stratified squamous epithelium with underlying tumour tissue exhibiting 'starry sky pattern' composed of macrophages dispersed amidst round to oval atypical cells. These cells have fine chromatin, prominent nucleoli and (fig.2a) abundant eosinophilic cytoplasm with few cells exhibiting membrane indentation. Numerous mitoses and apoptotic bodies were also seen (fig.2b). Diffuse sheets of cells was seen infiltrating the mucosa and palatal bone. The histology of post auricular swelling showed an effaced architecture of lymph node with tumour tissue of similar morphology as that of intraoral swelling. The presence of starry sky pattern, numerous apoptotic bodies and mitotic figures prompted us a possibility of Burkitt's lymphoma. Meanwhile, the peripheral blood smear examination revealed a high WBC count of 74,000 with $47 \%$ myeloblasts .
Following immunomarkers were run using flow cytometry. Markers for myeloid differentiation like CD45, CD68, $\mathrm{CD} 15$, MPO, and CD43 were strongly positive whereas lymphoid markers like Tdt, CD99 and CD20 were negative. CD10 showed weak positivity. Ki 67 showed a proliferation index of 65 percent (fig.3a - fig.3d). FISH analysis for $\mathrm{C}$-myc was negative and ruled out Burkitt's lymphoma. After considering histomorpholgy, immunohistochemistry and peripheral smear picture of AML, we arrived at a diagnosis of myeloid sarcoma concurrent with AML. Correlative bone marrow examination for subtyping AML could not be done in this case as the patient's parents got the child discharged against medical advice and was lost to follow up.

\section{DISCUSSION}

Myeloid sarcoma was first described by the British physician Burns in 1811. King coined the term chloroma in 1853 as these tumors often have a green tint due to the presence of myeloperoxidase (from the Greek word "chloros" meaning green). The relationship of MS with acute leukemia was established by Dock in 1892 . The first case of myelocytic leukemia associated with chloroma was reported by Turk et al in 1903. As 30\% of 


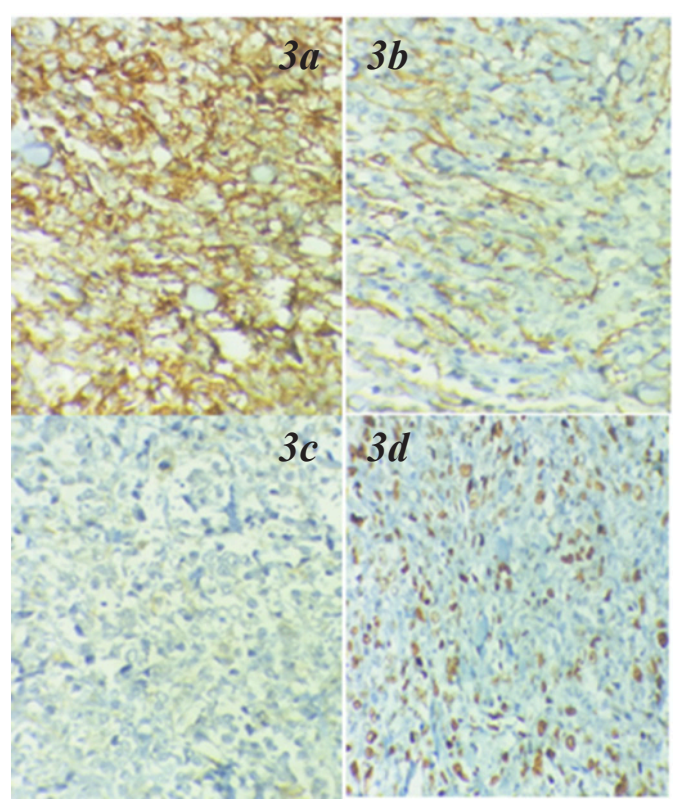

Figure 3: Photomicrograph showing CD 45 strong positive (a), CD10 weak positive (b), Tdt negative (c) and Ki 67 showing high proliferation index (d).

these tumors can be white, grey or brown rather than green, the more correct term 'granulocytic sarcoma' was proposed by Rappaport in 1966.

Liron et al, in 2005 reported that MS could occur in any one of three clinical settings: 1) In patients who have a history of AML, during active disease or a recurrence; 2) in patients with chronic myeloproliferative disorders (MPD), who are at increased risk of blast transformation or 3) in patients with no history of hematologic disease, although it commonly predates the development of leukemia, often within one year. ${ }^{3}$ Incidence of MS is reported to be 1 to $9 \%$ of patients with AML. It is more common in children and young adults with no difference between genders. ${ }^{4}$

Myeloid sarcoma can present as solitary or multifocal lesion, most cases manifest as isolated single lesions. The most common sites of extramedullary involvement include the skin (leukemia cutis), lymph node, and bone, but any organ in the body can be involved. Myeloid sarcoma involving the female reproductive tract, breast, gut, and testis have been reported in the literature. In the head and neck region, MS accounts for $12 \%-48 \%$ of the cases and orbits are commonly involved. ${ }^{5}$ Localisation in oral cavity is rare. ${ }^{2}$ Approximately about 45 cases of intraoral MS have been reported from 1881 till now. ${ }^{6}$

Most common intraoral location are maxillary and mandibular gingiva and bones; followed by cheek, tongue, tonsils, parotid, hard palate, soft palate and lip. ${ }^{2}$

It is believed that MS begins in the bone marrow and reaches the subperiosteum through Haversian channels and then spread to other parts of the body.

Myeloid sarcoma may be misdiagnosed since it can mimic lymphoma or an undifferentiated carcinoma. The differential diagnosis of MS in the head and neck region includes several types of malignant lymphoma (B-cell and T-cell) and small blue cell tumors of childhood. ${ }^{7}$ The most common error is to misdiagnose cases of MS as diffuse large B-cell lymphoma (DLBCL), particularly in cases of immature MS where there is lack of differentiation. However in DLBCL, cells have thick nuclear membrane with basophilic nucleoli while MS cells have thin nuclear membrane with pinpoint nucleoli. Also DLBCL express pan-B-cell antigens and negative for myeloid antigens. Epithelial origin of the tumour can be ruled out by cytokeratin negativity. Though CD99 expression is seen in a few subsets of MS and paediatric small blue cell tumours, negative myeloid antigens and MPO differentiate the two conditions. It has also been reported that MS also can exhibit a prominent starry-sky appearance with numerous apoptotic cells and mitoses and resemble Burkitt lymphoma. ${ }^{7}$

However, immunohistochemical studies distinguish MS from Burkitt lymphoma as Burkitt is positive for pan-Bcell antigens, CD10, BCL-6 and is negative for myeloid antigens. The most commonly expressed positive markers for MS are CD68/KP1, followed by MPO, CD117, CD99, CD68, lysozyme, CD34, TdT, CD56, CD61, CD30, glycophorin and CD4. For myeloid differentiation of MS, CD13, CD33, CD117 and MPO are the common markers. CD14, CD163 and CD11c are the common markers used for monoblastic differentiation. In addition, flow cytometry and cytogentics help to improve the likelihood of correct definitive diagnosis.

The diagnosis of MS may be difficult when it occurs in the oral cavity. When such innocuous appearing lesions are confronted in the gingiva, a high percentage of the chances is that these lesions are diagnosed as periodontal abscesses, pyogenic granuloma, carcinoma or lymphomas. As in the present case, history of fall on the face coincided with the gingival tumour and superadded inflammation of tooth extraction. Temporary response due to anti-inflammatory drugs and antibiotics was also noted. In this case, lymph node involvement and inflamed gingival mass mislead the diagnosis as Non Hodgkins lymphoma. It is the immunophenotyping by flow cytometry revealed the true nature of the lesion. Literature review reveals a few cases with involvement of both soft tissue and lymph node ${ }^{2,8,9}$ as in our case. It is worth mentioning that Goteri et al. emphasized a clinical diagnostic suspicion of myeloid sarcoma for accurate 
diagnosis whenever an extramedullary mass appears in a patient with a hematological disorder. ${ }^{10}$

\section{CONCLUSION}

Myeloid sarcoma can present with a 'starry sky pattern' and thus misleading the diagnosis as Burkitt lymphoma. Immunophenotyping of many hemopoietic lesions help in subtyping which in turn helps in the targeted chemotherapy and hence better management.

\section{Conflict of Interest: None}

\section{REFERENCES}

1. Chan A C L, Chan J K C, Cheung M M C, Kapadia S B. Hematolymphoid tumours. In: Barnes L, Eveson J W, Reichart P, SidranskyD(Eds): World Health Organisation Classification of Tumours. Pathology and Genetics of Head and Neck Tumours. IARC Press:Lyon 2005

2. Kurdoglu B, Oztemel A, Baris E, Sengüven B. Primary oral myeloid sarcoma: Report of a case. Journal of Oral and Maxillofacial Pathology.2013;17:413-6. Crossref

3. Pantanowitz L, Thompson L. Myeloid sarcoma. Ear Nose Throat J 2005;84:470-1 Crossref

4. Alexiev AB, Wang W, and Zhao FX. Myeloid Sarcoma: a Histologic, Immunohistochemical and cytogenetic study. Diagn Pathol 2007;2:42. Crossref
5. Jayabackthan L, Jayprakash C, Nisha JM, Muktha RP. A rare case of Myeloid Sarcoma presenting as nasal cavity mass. Iranian Journal of Pathology.2014;9:273-6

6. Thayalan D, Vemuri S, Ramadas R, Krishnan R . Primary intraoral granulocytic sarcoma: A rare case presenting as generalized gingival enlargement. J. Oral Maxillofac. Pathol.. 2016;20:523-6. Crossref

7. Sengupta M, Das I, Chatterjee U, Majumdar B. Denovo myeloid sarcoma involving mandible in a child:Report of a rare occurrence. J. Oral Maxillofac. Pathol. 2016:20;304-7. Crossref

8. Fiorillo A, de Rosa G, Canale G, Fariello I, D'Amore R, Bonavolontà G. Granulocytic sarcoma in nonleukemic children: report of two new cases successfully treated by local radiation therapy and systemic chemotherapy. Haematologica. 1996;81:1558. Crossref

9. Koudstaal MJ, Van der Wal KG, Lam KH, Meeuwis CA, Speleman L, Levin MD. Granulocytic sarcoma (chloroma) of the oral cavity: Report of a case and literature review. Oral Oncology EXTRA. 2006;42:70-7. Crossref

10. Goteri G, Ascani G, Messi M, et al . Myeloid sarcoma of the maxillary bone. J Oral Pathol Med. 2006;35:254-6. Crossref 